\title{
Molecular cophylogenetic relationships between European bats and their ectoparasitic mites (Acari, Spinturnicidae)
}

\author{
Nadia Bruyndonckx ${ }^{\mathrm{a}, *}$, Sylvain Dubey ${ }^{\mathrm{b}}$, Manuel Ruedi ${ }^{\mathrm{c}}$, Philippe Christe ${ }^{\mathrm{a}}$ \\ a Department of Ecology and Evolution, University of Lausanne, CH 1015 Lausanne, Switzerland \\ ${ }^{\mathrm{b}}$ Heydon-Laurence Bld, A08, Science Road, School of Biological Sciences, University of Sydney, Sydney, NSW 2006, Australia \\ ${ }^{\mathrm{c}}$ Natural History Museum of Geneva, CP 6434, 1208 Geneva, Switzerland
}

\section{A R T I C L E I N F O}

\section{Article history:}

Received 20 May 2008

Revised 3 February 2009

Accepted 16 February 2009

Available online 21 February 2009

\section{Keywords:}

Cophylogeny

Failure to speciate

Host specificity

Host switch

Mitochondrial 165 and COI genes

Spinturnix

\begin{abstract}
A B S T R A C T
Cospeciation between host-parasite species is generally thought to result in mirror-image congruent phylogenies. Incongruence can be explained by mechanisms such as host switching, duplication, failure to speciate and sorting events. To investigate the level of association in the host-parasite relationship between Spinturnicid mites and their bat hosts, we constructed the phylogenetic tree of the genus Spinturnix (Acari, Mesostigmata) and compared it to the host phylogeny. We sequenced $938 \mathrm{bp}$ of the mitochondrial 16S rDNA and Cytochrome Oxydase subunit I (COI) genes among eleven morphospecies of Spinturnix collected on 20 European Vespertilionid and Rhinolophid bat species. Phylogenetic reconstruction of hosts and parasites showed statistical evidence for cospeciation and suggested that their evolutionary history involved also failure to speciate events and host switches. The latter seem to be mainly promoted by similar roosting habits of the host. As currently understood, host associations of Spinturnicid mites likely results from a complex interaction between the phylogenetic history of the host and the behaviour and the ecology of both parasite and host.
\end{abstract}

(c) 2009 Elsevier Inc. All rights reserved.

\section{Introduction}

Speciation is an evolutionary process leading to the separation of a single species into two or more daughter species. For free-living organisms, speciation is the consequence of a number of extrinsic and intrinsic factors including interaction with complex ecosystem (Paterson and Banks, 2001), while for many parasites, the environment is mainly restricted to the body of their hosts (Gandon and Van Zandt, 1998; Sheeler-Gordon and Owen, 1999). Parasite speciation will thus largely depend on speciation events of its host, and the more host specific is a parasite, the more cospeciation events will occur (Nadler, 1995; Poulin et al., 2006). Consequently, the reconstruction of the evolutionary history of a parasite involved the one of its host. This approach is known as cophylogeny (Paterson and Banks, 2001).

Two main categories of events have been proposed to explain the current association between a parasite and its host (Brooks and McLennan, 1991): association by descent, where the parasite is inherited from the parent to the infant within a lineage, and association by colonization, where the parasite switches from the ancestral host to a new, unrelated host species. The first category involves cospeciation/codivergence events (Ronquist, 2003), where parasite speciates in response to the speciation of its host. This is

\footnotetext{
* Corresponding author. Fax: +41 216924165.

E-mail address: nadia.bruyndonckx@unil.ch (N. Bruyndonckx).
}

similar to vicariant events in biogeography (Brooks and McLennan, 1991; Page and Charleston, 1998), where an ancestral panmictic population becomes fragmented by a geographic barrier. This barrier limits gene flow between the daughter populations and may eventually lead to the formation of new species. The phylogenetic outcome of cospeciation events is the congruence between host tree and parasite tree (Hafner and Nadler, 1988; Hafner and Page, 1995). Incongruencies between host and parasite phylogenies are interpreted in terms of parasite duplication (i.e. speciation in the parasite without host speciation), sorting (i.e. random extinctions) or failure of the parasite to speciate after speciation of the host (Clayton et al., 2003; Johnson et al., 2003; Page, 1994; Paterson and Banks, 2001). In contrast, the second category of events, association by colonization, implies the horizontal transfer of the parasite from an ancestral host to a new host species. This process, also known as "host switching", is similar to the colonization of a new habitat by free-living organisms. Host switches also result in incongruent host and parasite phylogenies (Brooks and McLennan, 1991). Thus, the current pattern of association between host and parasite may result from a subtle combination of all these events.

The degree of association between hosts and parasites, and indirectly their degree of coevolution could depend on several nonexclusive factors, like ecological requirements of the host or the parasite, and on historical events (Huyse et al., 2005; Poulin et al., 2006; Vinarski et al., 2007). Hosts represent heterogeneous environments (Gandon et al., 1996) as they vary in quality (Christe 
et al., 2003), abundance and spatial distribution (Tripet et al., 2002). In turn, parasites range from generalists to specialists according to the number of host species they infect (Combes, 1991). Host specificity should evolved if it is more advantageous to live on a single host species rather than on several ones (Jaenike, 1990; McCoy et al., 2001). This parasite specialization should thus be favored with the increase of host abundance and predictability (Combes, 1997; Jaenike, 1990; McCoy et al., 2001; Thompson, 1994). A recent study showed that the differences in regional abundances of the hosts (A. flavicollis and A. sylvaticus) could generate a regional co-differentiation pattern of the parasite (Heligmosomoides) (Nieberding et al., 2008). Parasite intrinsic dispersal ability is another important factor involved in host specialization. Indeed, the number of host species a parasite could colonize is directly linked to its dispersal capacity (Gandon et al., 1996; Ward et al., 1998), as far as benefits to disperse on new host species outweigh the costs (Dick and Patterson, 2007). Finally, a mobile host species that avoids infested roosts represents another barrier to mite dispersal (Reckardt and Kerth, 2007).

Cophylogenetic studies between small mammals and their parasites are still scant and led to contrasting conclusions. For example, Hafner and Nadler (1988) showed a high level of cospeciation between rodents (Geomyidae) and lice (Geomydoecus and Thomomydoecus), Nieberding et al. (2005, 2004, 2008) found a congruent pattern between field mouse (Apodemus sylvaticus) and one of its specific endoparasitic nematode (Heligmosomoides polygyrus) in southwestern Europe, whereas Krasnov and Shenbrot (2002) found that host switching better explains the coevolutionary history of jerboas (Dipodidae) and ectoparasitic fleas (Siphonaptera). The latter study suggests that host switching of fleas has been common on jerboas and that the distribution of fleas is mainly affected by the distribution and ecological characteristics of the host. It is thus important to account for ecological and geographical factors when drawing general patterns of cophylogenetic relationships between small mammals and their parasites. Here, we investigate a host- parasite system involving different species of bats and their mites (Acari, Spinturnicidae) to shed light on the evolution of their associations.

Parasitic mites of the family Spinturnicidae (Acari, Mesostigmata) are ectoparasites specialized on bats (Rudnick, 1960). The last century, their taxonomy underwent many rearrangements and currently 13 Spinturnix species are recognized in Europe (Deunff, 1977; Deunff et al., 1986, 1997; Deunff et al., 1990; Deunff et al., 2004; Kolenati, 1856; Rudnick, 1960; Stanyukovich, 1997). Spinturnix mites are obligate parasites completing their entire life cycle on membranous regions of their host's body (Rudnick, 1960). In the Palaearctic region, they display different levels of host specificity, ranging from one to several host species (Baker and Craven, 2003; Christe et al., 2003; Deunff, 1977). As mites cannot live away from their host for more than a few hours, mite transmission and dispersal strongly depend on host body contacts (Deunff, 1977; Giorgi et al., 2004). Thus, they constitute an interesting model to study the joint impact of phylogeny and host environmental conditions on the distribution of a parasite on its host.

In this study, we investigated the relationships among Spinturnix mites using two mitochondrial DNA genes. We tested for mites and bats cospeciation using distance-based methods and compared phylogenies to detect which evolutionary events are involved in this association and to understand how they occurred.

\section{Materials and methods}

\subsection{Sampling}

Seventy-eight Spinturnix mites from 20 European bat species were sampled in Switzerland, France, Spain and Italy between years 2004 and 2006 (Fig. 1). To minimize problems with host or parasite misidentification or with artificial cross-contamination of hosts, the following precautions where taken: Bat species were identified morphologically by specialists using conventional keys

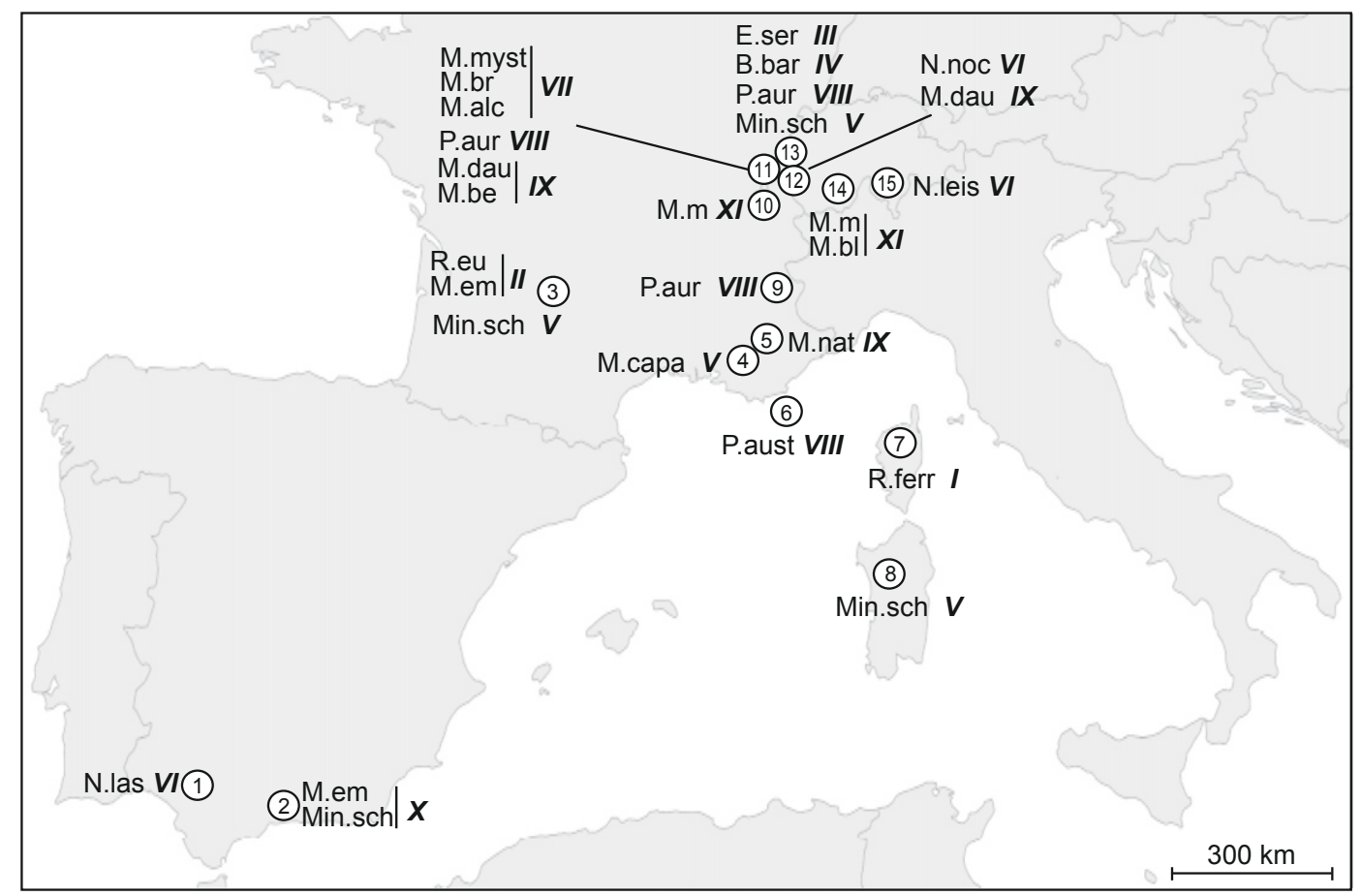

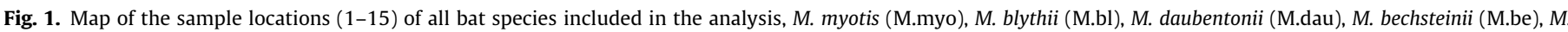

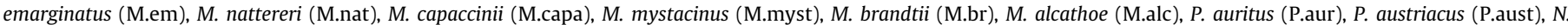

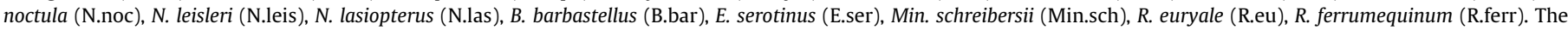
roman numbers indicate which mite genetic clade was present on which bat species at which location. 
(Dietz et al., 2007; Schober and Grimberger, 1991) and in case of doubt, genetic analyses were performed. These bats include 18 species of the family Vespertilionidae and two Rhinolophidae (Table 1). All bats were kept in separated bags to avoid parasite cross-contamination. Mites were collected with soft forceps from the wing membranes of their hosts, preserved in $90 \%$ ethanol and stored at $-20^{\circ} \mathrm{C}$ until use. Mite species were identified with a key of gamasid mites (Stanyukovich, 1997) and with papers of Deunff (1977) and Deunff et al. (2004). We also took pictures from specimens, especially for mite species represented by only one individual, in case a re-examination was needed. Mites represent 11 different species of Spinturnix and one species of a closely related genus, Eyndhovenia (Table 1). The only two other known European spinturnicid species not sampled here are $S$. bakeri and S. nobleti, which are specific to Pipistrellus kuhlii and Hypsugo savii, respectively.

\subsection{DNA extraction and amplification}

Specimens were individually rehydrated during $2 \mathrm{~h}$ in $200 \mu \mathrm{l}$ of sterile water before being crushed in liquid nitrogen. Total DNA was isolated from a single mite using a standard proteinase $\mathrm{K}$, phenol chloroform method (Sambrook et al., 1989). Amplification of the 16S rRNA gene (16S) was performed with the primer pair 16S+1/16S-1 described in Mangold et al. (1998) and Norris et al. (1996). Amplification of the cytochrome oxydase subunit I (COI) gene was performed with the primer pair C1-J-2183 (Simon et al., 1994) and C1-J-2797mod (3'-GGA TAA TCT GAA TAA CGT CGA GG-5', modified from Simon et al., 1994) for all mite species, except for S. helvetiae, S. acuminata, S. psi, and S. mystacina. For these four mite species, a new primer pair was specially designed: M1-J-2216 (5'-TGA AGT GTA TAT TTT AAT TTT ACC TGG-3') and SD1 (5'-GGT ATT CCT CTT AGT CC-3'). All polymerase chain reactions (PCR) were performed in $25 \mu \mathrm{L}$ of reaction mixture containing $2 \mu \mathrm{L}$ of extracted DNA, $0.2 \mathrm{mM}$ deoxynucleoside triphosphate (dNTP), $1.5 \mathrm{mM} \mathrm{MgCl}_{2}, 0.32 \mu \mathrm{M}$ of each primer, $1 \times$ QIAgen PCR buffer (with $\mathrm{MgCl}_{2} 15 \mathrm{mM}$ ) and 0.04U QIAgen Taq polymerase (Qiagen). PCRs were run in a PTC-100 thermocycler (MJ reasearch) with a cycling profile as follows: initial denaturation at $94^{\circ} \mathrm{C}$ for $2 \mathrm{~min}$, followed by 40 cycles of $30 \mathrm{~s}$ denaturation at $94^{\circ} \mathrm{C}, 30 \mathrm{~s}$ annealing at $47^{\circ} \mathrm{C}, 45 \mathrm{~s}$ elongation at $72{ }^{\circ} \mathrm{C}$ for, and a final elongation at $72{ }^{\circ} \mathrm{C}$ for $10 \mathrm{~min}$. Five microliters of the PCR products were electrophoresed on a $1.5 \%$ agarose gel and visualized with ethidium bromide staining to verify the amplification. Amplified DNA was purified using the QIAquick PCR purification Kit (Qiagen) and eluted in $30 \mu \mathrm{L} \mathrm{dH}_{2} \mathrm{O}$. Sequencing reactions were performed in a $10 \mu \mathrm{L}$ volume containing $1 \mu \mathrm{L}$ of purified DNA, $0.25 \mathrm{mM}$ of forward or reverse primer and $2 \mu \mathrm{L}$ of BigDye Terminator Kit v1 (PerkinElmer). Sequencing of both strands was performed with a cycling profile of 35 cycles of $15 \mathrm{~s}$ denaturation at $96^{\circ} \mathrm{C}, 15 \mathrm{~s}$ annealing at $47^{\circ} \mathrm{C}$ and $3 \mathrm{~min}$ elongation at $60^{\circ} \mathrm{C}$. Products were analyzed on an ABI Prism 3100 genetic analyzer (Applied Biosystems).

\subsection{Mite phylogenetic analyses}

Conspecific mites from one to nine distinct specimens for each host species were sequenced. Sequences of the mitochondrial COI and 16S genes were aligned and edited with Sequence Navigator (Parker, 1997) and deposited in GenBank under Accession Nos. EU784846-EU784953 (Table 1). Due to the limitations of the Incongruence Length Difference (ILD) test (Struck et al., 2006; Wheeler et al., 2006; Yoder et al., 2001), the congruence between the two markers was tested by performing 1000 bootstrap re-samples on each marker with a maximum parsimony (MP) criterion, and comparing the support level thus obtained for each node. The two DNA sequences were combined only if all supported nodes (defined here by bootstrap values $>75 \%$ ) were present in all two obtained trees (e.g. Barrett et al., 1991; Cunningham, 1997; Dubey et al., 2007; Halanych, 1998; Huelsenbeck et al., 1996; MasonGamer and Kellogg, 1996; Struck et al., 2006). This congruence test showed that no node with bootstrap higher than $75 \%$ was contradicted by the two partition datasets (data not shown). We thus considered that both markers could be combined for further analyses.

Trees were rooted using homologous sequences of Varroa destructor (Acari, Varroidae), deposited in GenBank under Accession No. AJ493124 (Navajas et al., 2002). V. destructor belongs to the same super family as Spinturnicidae (Dermanyssoidea) (Klompen et al., 2007) and is the closest species where $16 \mathrm{~S}$ and COI sequences were available. The most appropriate model of DNA substitution was determined using MrModeltest 2.2 (Nylander, 2006) and a hierarchical likelihood ratio tests (hLRTs). This model was a GTR + I + G (Rodriguez et al., 1990; Yang, 1996) with base frequencies, $A=0.3587, C=0.1254, G=0.07737, T=0.4423$; gamma shape parameter, $G=0.4328$; and proportion of invariable site, $I=0.4672$. Four different methods of phylogenetic reconstructions were used to infer the evolution of mite lineages: a distance method (neighbour-joining tree (NJ) with GTR genetic distances), a parsimony method (maximum parsimony tree (MP) with heuristic searches, 10 random addition of taxa, and TBR branch swapping (Swofford, 1998); all codon positions were equally weighted), a maximum likelihood method (ML) and Bayesisan approach (BA). The first two methods were carried out with PAUP* version $4.0 \mathrm{~b} 10$ (Swofford, 1998), while ML searches were performed with PHYML (Guindon and Gascuel, 2003) with the parameters of the substitution model suggested by MrModeltest. Bootstrap support values were obtained with 1000 pseudo-replicates and 10,000 for ML analysis. Finally, the Bayesian analyses (BA) were performed with MrBayes version 3.1.2 (Huelsenbeck et al., 2001). A GTR model was used, with an among-site rate variation following a gamma distribution. The Markov chain was run for 10,000,000 generations and sampled once every 10,000 generations; burn-in was set to the first 250 trees, allowing a good convergence of the independent runs (the average standard deviation of split frequencies being lower than 0.01 ). Posterior probability values (PP) were calculated on the consensus of 750 trees. To ensure convergence in the BA, two independent runs were performed. Nucleotide diversity and mean pairwise K2P distances among and within clades were calculated using the software MEGA version 3.1 (Kumar et al., 2004). To investigate the delimitation of the morphospecies, mean K2P distances were also performed between and within the 11 morphospecies.

\subsection{Host phylogeny and cophylogenetic comparisons}

Reconstructing the complete bat phylogeny, including such divergent families as Rhinolophidae or Vespertilionidae is notoriously difficult as it spans over an evolutionary period of more than 60 million years (Miller-Butterworth et al., 2007; Teeling et al., 2005). On the other hand, several host bats included here are very closely related (e.g. various Myotis species), and thus no single gene or combination of genes could be used to resolve adequately the phylogeny of all bats in a single analysis. To overcome this problem, we therefore recovered from the literature the topology of various trees representing interfamilial (Hoofer and Van den Bussche, 2003; Miller-Butterworth et al., 2007) or intrageneric relationships (Juste et al., 2004; Ruedi and Mayer, 2001; Stadelmann et al., 2004) of the species sampled in our study to build a bat cladogram. However, we used $1140 \mathrm{bp}$ of the mitochondrial cytochrome $b$ gene available in GenBank to calculate pairwise divergences between bat species (Ibanez et al., 2006; Juste et al., 2004; Juste et al., 2003; Li et al., 2006; Ruedi and Mayer, 2001; Stadelmann et al., 2004). 
Table 1

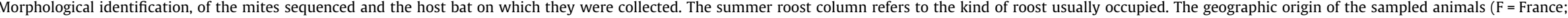

$\mathrm{CH}=$ Switzerland; E = Spain; I = Italy) with latitudinal/longitudinal coordinates and the designation of the different haplotypes with Accession Nos. of COI-16S sequences are also given.

\begin{tabular}{|c|c|c|c|c|c|c|}
\hline Mite species & Host species & Summer roost & Sample location & Lat/Long & Haplotype - ID code & Accession Nos. (16S/COI) \\
\hline Eyndhovenia euryalis & Rhinolophus euryale & Cave & 3-Magnagues, $\mathrm{F}$ & $44^{\circ} 53^{\prime} 58.18^{\prime \prime N} / 01^{\circ} 44^{\prime} 26.64^{\prime \prime} \mathrm{E}$ & E. euryalis 1 & EU784846-EU784900 \\
\hline Eyndhovenia euryalis & Rhinolophus euryale & Cave & 3-Magnagues, $\mathrm{F}$ & & E. euryalis 2 & EU784847-EU784901 \\
\hline Eyndhovenia euryalis & Myotis emarginatus & Cave & 3-Magnagues, $\mathrm{F}$ & & E. euryalis 3 & EU784849-EU784903 \\
\hline Eyndhovenia euryalis & Myotis emarginatus & Cave & 3-Magnagues, $\mathrm{F}$ & & E. euryalis 3 & EU784849-EU784903 \\
\hline Eyndhovenia euryalis & Myotis emarginatus & Cave & 3-Magnagues, $\mathrm{F}$ & & E. euryalis 4 & EU784848-EU784902 \\
\hline Eyndhovenia euryalis & Myotis emarginatus & Cave & 3-Magnagues, $\mathrm{F}$ & & E. euryalis 5 & EU784850-EU784904 \\
\hline Eyndhovenia euryalis & Rhinolophus euryale & Cave & 3-Magnagues, $\mathrm{F}$ & & E. euryalis 6 & EU784851-EU784905 \\
\hline Eyndhovenia euryalis & Rhinolophus euryale & Cave & 3-Magnagues, F & & E. euryalis 7 & EU784852-EU784906 \\
\hline Eyndhovenia euryalis & Rhinolophus ferrumequinum & Cave & 7-Oletta, Corse, F & $42^{\circ} 38^{\prime} 0.26^{\prime \prime} \mathrm{N} / 09^{\circ} 21^{\prime} 18.85^{\prime \prime} \mathrm{E}$ & E. euryalis 8 & EU784853-EU784907 \\
\hline Eyndhovenia euryalis & Rhinolophus ferrumequinum & Cave & 7-Oletta, Corse, F & & E. euryalis 8 & EU784853-EU784907 \\
\hline Spinturnix helvetiae & Nyctalus leisleri & Tree & 15-Alto Malcantone, $\mathrm{CH}$ & $46^{\circ} 02^{\prime} 52.70^{\prime \prime} \mathrm{N} / 08^{\circ} 53^{\prime} 49.41^{\prime \prime} \mathrm{E}$ & S. helvetiae & EU784855-EU784909 \\
\hline Spinturnix acuminata & Nyctalus lasiopterus & Tree & 1-Sevilla, E & $37^{\circ} 23^{\prime} 0.63^{\prime \prime} \mathrm{N} / 05^{\circ} 59^{\prime} 47.02^{\prime \prime} \mathrm{O}$ & S. helvetiae & EU784855-EU784909 \\
\hline Spinturnix acuminata & Nyctalus noctula & Tree & 12-Dorigny, CH & $46^{\circ} 31^{\prime} 24.14^{\prime \prime} \mathrm{N} / 06^{\circ} 34^{\prime} 36.59^{\prime \prime} \mathrm{E}$ & S. acuminata 1 & EU784856-EU784910 \\
\hline Spinturnix acuminata & Nyctalus noctula & Tree & 12-Dorigny, $\mathrm{CH}$ & & S. acuminata 2 & EU784857-EU784911 \\
\hline Spinturnix acuminata & Nyctalus lasiopterus & Tree & 1-Sevilla, E & & S. acuminata 3 & EU784858-EU784912 \\
\hline Spinturnix andegavinus & Myotis daubentonii & Tree & 12-Dorigny, $\mathrm{CH}$ & & S. andegavinus 1 & EU784873-EU784927 \\
\hline Spinturnix andegavinus & Myotis daubentonii & Tree & 12-Dorigny, $\mathrm{CH}$ & & S. andegavinus 2 & EU784874-EU784928 \\
\hline Spinturnix andegavinus & Myotis daubentonii & Tree & 11-Jura mountains, $\mathrm{CH}$ & $46^{\circ} 32^{\prime} 12.62^{\prime \prime} \mathrm{N} / 06^{\circ} 10^{\prime} 32.84^{\prime \prime} \mathrm{E}$ & S. andegavinus 3 & EU784875-EU784929 \\
\hline Spinturnix andegavinus & Myotis daubentonii & Tree & 11-Jura mountains, $\mathrm{CH}$ & & S. andegavinus 3 & EU784875-EU784929 \\
\hline Spinturnix andegavinus & Myotis daubentonii & Tree & 11-Jura mountains, $\mathrm{CH}$ & & S. andegavinus 3 & EU784875-EU784929 \\
\hline Spinturnix andegavinus & Myotis daubentonii & Tree & 12-Dorigny, $\mathrm{CH}$ & & S. andegavinus 4 & EU784877-EU784931 \\
\hline Spinturnix andegavinus & Myotis daubentonii & Tree & 12-Dorigny, CH & & S. andegavinus 5 & EU784878-EU784932 \\
\hline Spinturnix andegavinus & Myotis daubentonii & Tree & 12-Dorigny, CH & & S. andegavinus 6 & EU784879-EU784933 \\
\hline Spinturnix andegavinus & Myotis daubentonii & Tree & 11-Jura mountains, $\mathrm{CH}$ & & S. andegavinus 7 & EU784876-EU784930 \\
\hline Spinturnix bechsteini & Myotis bechsteinii & Tree & 11-Jura mountains, $\mathrm{CH}$ & & S. bechsteini & EU784882-EU784936 \\
\hline Spinturnix bechsteini & Myotis bechsteinii & Tree & 11-Jura mountains, $\mathrm{CH}$ & & S. bechsteini & EU784882-EU784936 \\
\hline Spinturnix bechsteini & Myotis bechsteinii & Tree & 11-Jura mountains, $\mathrm{CH}$ & & S. bechsteini & EU784882-EU784936 \\
\hline Spinturnix bechsteini & Myotis bechsteinii & Tree & 11-Jura mountains, $\mathrm{CH}$ & & S. bechsteini & EU784882-EU784936 \\
\hline Spinturnix myoti & Myotis nattereri & Tree & 5-Verdon, $\mathrm{F}$ & $43^{\circ} 49^{\prime} 60.28^{\prime \prime} \mathrm{N} / 06^{\circ} 05^{\prime} 26.50^{\prime \prime} \mathrm{E}$ & S. myoti 11 & EU784880-EU784934 \\
\hline Spinturnix myoti & Myotis nattereri & Tree & 5-Verdon, $\mathrm{F}$ & & S. myoti 12 & EU784881-EU784935 \\
\hline Spinturnix myoti & Myotis blythii & Cave & 14-Naters, CH & & S. myoti 1 & EU784883-EU784937 \\
\hline Spinturnix myoti & Myotis myotis & Cave & 11-Jura mountains, $\mathrm{CH}$ & & S. myoti 1 & EU784883-EU784937 \\
\hline Spinturnix myoti & Myotis blythii & Cave & 14-Naters, CH & $46^{\circ} 19^{\prime} 32.84^{\prime \prime} \mathrm{N} / 07^{\circ} 59^{\prime} 17.62^{\prime \prime} \mathrm{E}$ & S. myoti 2 & EU784884-EU784938 \\
\hline Spinturnix myoti & Myotis blythii & Cave & 14-Naters, CH & & S. myoti 3 & EU784885-EU784939 \\
\hline Spinturnix myoti & Myotis blythii & Cave & 14-Naters, CH & & S. myoti 3 & EU784885-EU784939 \\
\hline Spinturnix myoti & Myotis myotis & Cave & 14-Naters, CH & & S. myoti 3 & EU784885-EU784939 \\
\hline Spinturnix myoti & Myotis myotis & Cave & 14-Naters, CH & & S. myoti 3 & EU784885-EU784939 \\
\hline Spinturnix myoti & Myotis myotis & Cave & 14-Naters, CH & & S. myoti 3 & EU784885-EU784939 \\
\hline Spinturnix myoti & Myotis myotis & Cave & 14-Naters, CH & & S. myoti 4 & EU784887-EU784941 \\
\hline Spinturnix myoti & Myotis blythii & Cave & 14-Naters, CH & & S. myoti 5 & EU784886-EU784940 \\
\hline Spinturnix myoti & Myotis myotis & Cave & 14-Naters, CH & & S. myoti 5 & EU784886-EU784940 \\
\hline Spinturnix myoti & Myotis myotis & Cave & 14-Naters, CH & & S. myoti 6 & EU784889-EU784943 \\
\hline Spinturnix myoti & Myotis myotis & Cave & 10-Satigny, $\mathrm{CH}$ & $46^{\circ} 12^{\prime} 48.11^{\prime \prime} \mathrm{N} / 06^{\circ} 02^{\prime} 8.15^{\prime \prime} \mathrm{E}$ & S. myoti 7 & EU784892-EU784946 \\
\hline Spinturnix myoti & Myotis myotis & Cave & 11-Jura mountains, $\mathrm{CH}$ & & S. myoti 8 & EU784891-EU784945 \\
\hline Spinturnix myoti & Myotis myotis & Cave & 14-Naters, CH & & S. myoti 9 & EU784888-EU784942 \\
\hline Spinturnix myoti & Myotis myotis & Cave & 14-Naters, CH & & S. myoti 9 & EU784888-EU784942 \\
\hline Spinturnix myoti & Myotis myotis & Cave & 11-Jura mountains, $\mathrm{CH}$ & & S. myoti 10 & EU784890-EU784944 \\
\hline Spinturnix emarginata & Myotis emarginatus & Cave & 2-Malaga, E & $36^{\circ} 52^{\prime} 24.40^{\prime \prime} \mathrm{N} / 04^{\circ} 04^{\prime} 55.35^{\prime \prime} \mathrm{O}$ & S. emarginata & EU784872-EU784926 \\
\hline Spinturnix emarginata & Miniopterus schreibersii & Cave & 2-Malaga, E & & S. emarginata & EU784872-EU784926 \\
\hline Spinturnix kolenati & Eptesicus serotinus & Cave/Tree & 13-Baulmes, CH & $46^{\circ} 47^{\prime} 45.30^{\prime \prime} \mathrm{N} / 06^{\circ} 31^{\prime} 14.24^{\prime \prime} \mathrm{E}$ & S. kolenati & EU784854-EU784908 \\
\hline Spinturnix mystacina & Myotis mystacinus & Tree & 11-Jura mountains, $\mathrm{CH}$ & & S. mystacina 1 & EU784862-EU784916 \\
\hline Spinturnix mystacina & Myotis mystacinus & Tree & 11-Jura mountains, $\mathrm{CH}$ & & S. mystacina 1 & EU784862-EU784916 \\
\hline Spinturnix mystacina & Myotis mystacinus & Tree & 11-Jura mountains, $\mathrm{CH}$ & & S. mystacina 2 & EU784863-EU784917 \\
\hline
\end{tabular}




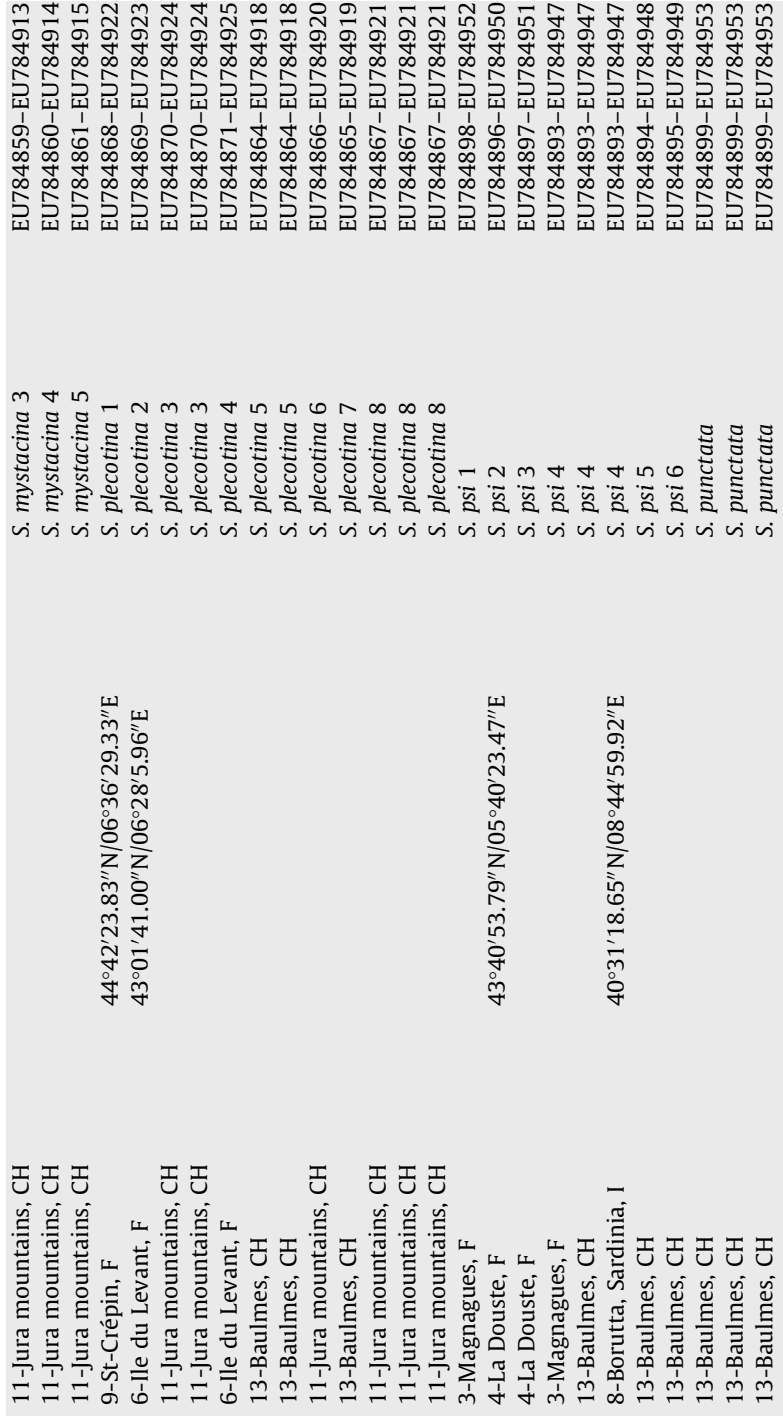

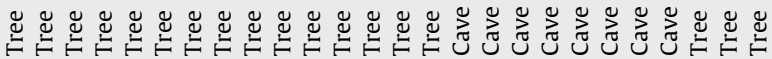
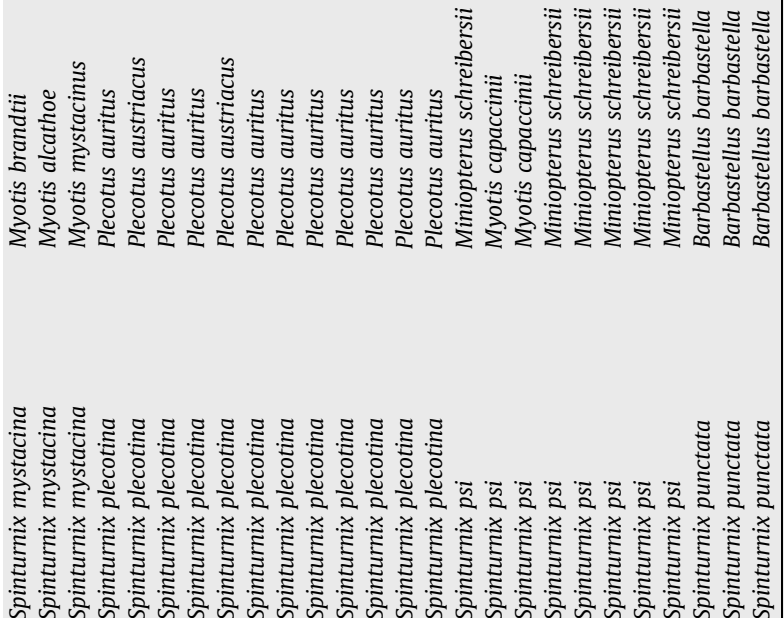

We tested the extent of a global hypothesis of coevolution between the mites and their hosts using ParaFit (Legendre et al., 2002), which uses the phylogenetic distances of host and parasite phylogenies transformed into principle coordinates (Gower, 1966). ParaFit can be used with trees presenting polytomies and is not affected by the presence of multiple parasites per host or multiple hosts per parasite. However, it does not yield any coevolutionary scenarios and does not identify cospeciation and host switching events on the phylogenies. We applied the model of sequence evolution selected by MrModeltest to calculate genetic distances between haplotypes for the mites $(G T R+I+G)$ and for the bats $(\mathrm{HKY}+\mathrm{G})$ using PAUP $*$. We converted distance matrices into principal coordinates using the program DistPCoA (Legendre and Anderson, 1998). Tests of random association in ParaFit were performed with 9999 permutations globally across both phylogenies (Desdevises et al., 2002).

To infer the direction of host switches, we used a maximum likelihood method implemented in MESQUITE version 1.05 (Maddison and Maddison, 2004). We used the bayesian tree of the mite and assigned to each mite haplotype the host genus on which the mite was collected. This method identified for each node the probability of each state to be ancestral; in our case the character state is the host genus. For each node, we obtained the probability of each host genus, i.e. Myotis, Plecotus, Nyctalus, Eptesicus, Miniopterus, Rhinolophus and Barbastella, to be the ancestor. S. emarginata was the only mite species that was sampled on two different host genera (Myotis and Miniopterus), we therefore run two distinct analyses, one with each of the two possible hosts assigned to $S$. emarginata. The model of character evolution was a simple stochastic model (Mk1, Lewis, 2001), which assumes a symmetric and equal rate of change between any two states. The probability that a character changes along a branch of the tree is then a function of the branch length, a change being more likely on longer branches than on shorter ones.

\section{Results}

\subsection{Mite phylogenetic analyses}

Eleven distinct species of Spinturnix and one of Eyndhovenia were identified by their external morphology, each represented by one to 19 specimens. The host-parasite association observed, type of summer roost occupied by the bats, sampling locations and their respective latitudinal/longitudinal coordinates are described in Table 1 . Out of the 78 mites sequenced, 54 appeared to have distinct haplotypes (Table 1 ). No insertion or deletion was observed in the alignment of COI sequences, whereas an insertion/deletion of $1 \mathrm{bp}$ was introduced at position 213 to accommodate the alignment of $16 \mathrm{~S}$ sequences of Eyndhovenia and Spinturnix. The final data set comprised $369 \mathrm{bp}$ of $16 \mathrm{~S}$ and $544 \mathrm{bp}$ of COI. These 913 aligned nucleotides consisted in 377 variable sites, of which 248 were parsimony-informative. As the four phylogenetic methods gave identical topologies for the main branches, only the Bayesian tree illustrating the relationships between haplotypes was shown, with bootstrap values from the other analyses (Fig. 2). Spinturnix and Eyndhovenia mites formed two distinct monophyletic clades. These genera were further subdivided in a total of 11 major clades, all highly supported by all methods ( $\geqslant 99 \%$ ). In contrast, the basal relationships of these 11 clades were not well supported (Fig. 2) and therefore will not be discussed.

The following list describes the detailed content of those clades. Clade I comprised a single divergent haplotype of Eyndhovenia euryalis that was found on a greater horseshoe bat (Rhinolophus ferrumequinum).

Clades II comprised all other haplotypes from E. euryalis that were sampled on two different host species, the Mediterranean 
horseshoe bats ( $R$. euryale) and on Geoffroy's bats (Myotis emarginatus).

Clade III included the single haplotype of Spinturnix kolenati found on a serotine bat (Eptesicus serotinus).

Clade IV included the single haplotype of $S$. punctata found on three different barbastelles (Barbastella barbastellus).
Clade V included all haplotypes of S. psi found on both Schreiber's bats (Miniopterus schreibersii) and long-fingered bats (Myotis capaccinii).

Clade VI included all haplotypes of mites found on three species of noctule bats: S. helvetiae on Leisler's bats (Nyctalus leisleri) and $S$. acuminata on common noctules (N. noctula) and on a giant noctule (N. lasiopterus).

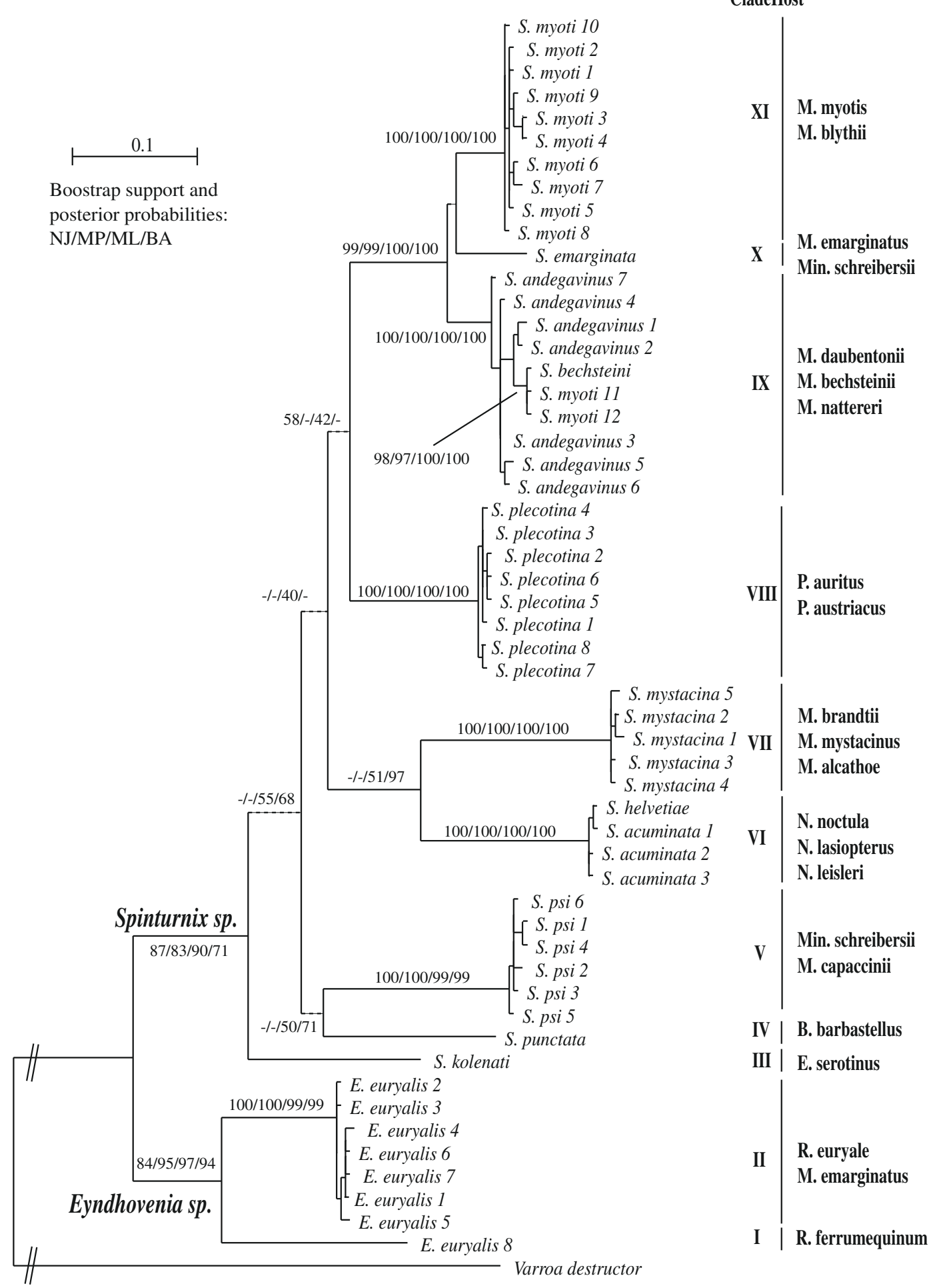

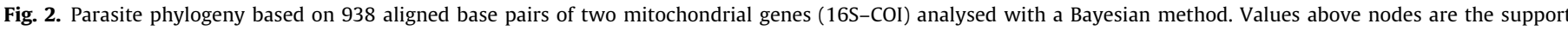

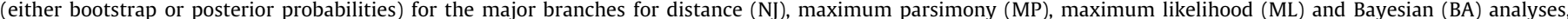

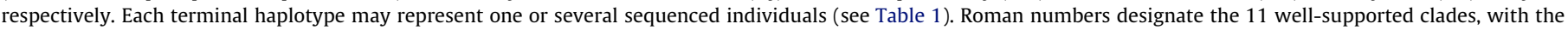
species name of the bat host appearing on the right 
Clade VII included haplotypes of S. mystacina found on whiskered bats (M. mystacinus), on a Brandt's bat (M. brandtii) and on an Alcathoe's bat (M. alcathoe).

Clade VIII included all haplotypes of S. plecotina found on two Plecotus species, i.e. on brown long-eared bats ( $P$. auritus) and on grey long-eared bats (P. austriacus).

Clade IX included a mixture of haplotypes of three distinct mite species: S. andegavinus, S. bechsteini and S. myoti found on Daubenton's bats ( $M$. daubentonii), on Bechstein's bats ( $M$. bechsteinii) and on Natterer's bats ( $M$. nattereri), respectively.

Clade X included haplotypes of S. emarginata, found on a Geoffroy's bat (M. emarginatus) and a Schreiber's bat (Min. schreibersii).

Clade XI finally included haplotypes of $S$. myoti found on two sister species of bats, the greater mouse-eared bat (M. myotis) and the lesser mouse-eared bat (M. blythii). This strongly supported clade of Spinturnix did not include two S. myoti haplotypes hosted by Natterer's bats both of which were part of clade IX (see Fig. 2).

Mean K2P distances between clades ranged from 5.3\% (IX and X, $\mathrm{X}$ and $\mathrm{XI}$ ) to $19.3 \%$ (I and IV). Within clades, K2P distances ranged from $0.2 \%$ (VI, VIII) to $0.8 \%$ (IX), and nucleotide diversities ranged from 0.257 (VI) to 0.0092 (IX). When haplotypes were grouped according to the morphospecies, mean K2P distances between groups $(0.1-17 \%)$ and within groups (0.2-2.5\%) overlapped considerably.

\subsection{Host and parasite cophylogeny}

The analyzed mite species did not appear to be strictly hostspecific as eight out of the 11 species infected several different bat species (clades II, V, VI, VII, VIII, IX, X and XI). On the other hand, most bat species harboured a single mite species, with the exception of Min. schreibersii and M. emarginatus, which can host two distinct mite species (Fig. 2). However, in both cases, bats were sampled in very distinct locations and never in sympatry (Table 1 ).

The distance-based method, ParaFit, rejected the null hypothesis that mites and their host have evolved independently $(p=0.003)$, indicating that there is significant cophylogenetic history. Conspecific mites found on closely-related bats (clade VI, VII, VIII, IX and XI, Fig. 3) may be explained by failure to speciate events while conspecific mites found on unrelated hosts (clade II, V, VII, IX and X) may be explained by host switches. However, our analysis did not permit to detect other events like duplication or extinction that could also play a role in this system. The ancestral state reconstruction suggested that the polarity of three host switches between different host genera were in the following direction (1) E. euryalis was more likely to switch from $R$. euryale to M. emarginatus (ML support of $65.8 \%$ when Myotis is considered as host for S. emarginata and $67.3 \%$ with Miniopterus) than the opposite (33.4\% and 32.1\%); (2) S. psi was more likely to switch from Min. schreibersii to M. capaccinii (92.8\% and 92.7\%) than the opposite (6.9\% and 7.2\%); (3) S. emarginata was more likely to switch from M. emarginatus to Min. schreibersii (76.1\% and $97.7 \%$ ) than the opposite $(9.2 \%$ and $0.4 \%)$.

\section{Discussion}

\subsection{Mite molecular phylogeny and taxonomy}

In this study, we reconstructed for the first time the phylogeny of European Spinturnicid mites based on molecular data. We found several inconsistencies with the current taxonomy based on morphological characters. Indeed, the considerable variability and

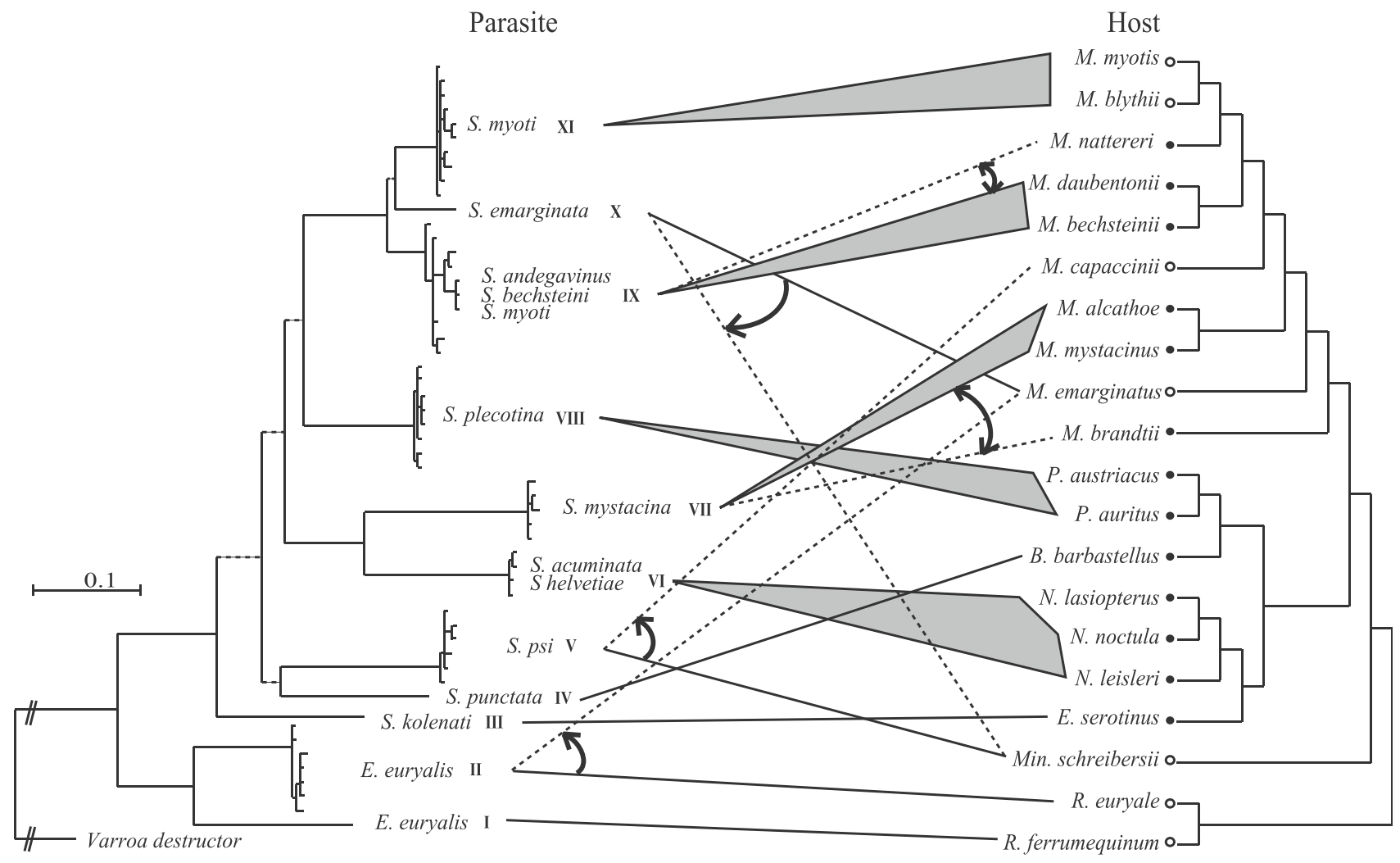

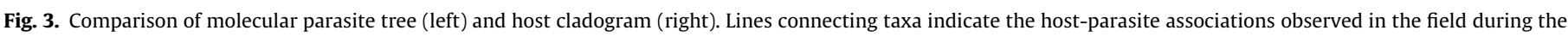

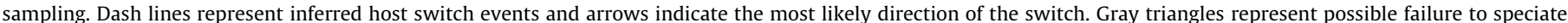

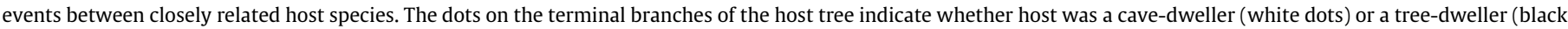
dots) bat. 
overlap of K2P distances within and between morphospecies indicate that morphological delimitation between species is not satisfactory. For instance, the high genetic differentiation between the most divergent haplotypes of E. euryalis (K2P: $8.4 \%$, clade I and II, Fig. 2) is of the same magnitude as the one between other Spinturnix morphospecies, which would suggest species status for both lineages. However, these mites were sampled both on distinct bat species ( $R$. euryale and $R$. ferrumequinum) and distinct geographic locations (mainland France and Corsica). It would therefore be necessary to sample E. euryalis where its hosts live in sympatry to determine if mites from these lineages behave as different species, each specific to a different host, or if they colonise both hosts indiscriminately. Conversely, mites sampled on noctule bats (clade VI, Fig. 2) and assigned morphologically to S. helvetiae and S. acuminata, do not differ genetically (Fig. 2). Deunff et al. (1986) described $S$. helvetiae as a new species specific to N. leisleri, and morphologically distinct from $S$. acuminata hosted by $N$. noctula. However, this taxonomic interpretation was challenged more recently by Uchikawa et al. (1994), who relegated S. helvetiae to a subspecies of $S$. acuminata. This taxonomic treatment is more consistent with the current genetic results (Fig. 2). Regarding S. bechsteini, Deunff et al. (2004) used biometrical and morphological criteria to discriminate it from $S$. myoti, and considered it as specific to the bat $M$. bechsteinii. Our genetic results indeed support the uniqueness of the haplotypes of Spinturnix mites found on the Bechstein's bats. However, their relationships relative to $S$. andegavinus and $S$. myoti are unclear (Fig. 2). The two Spinturnix hosted by Natterer's bats and assigned morphologically to $S$. myoti (i.e. S. myoti 11 and S. myotis 12 in Fig. 2) were much more closely related to S. bechsteini than to other S. myoti found on the bats M. myotis and M. blythii (S. myoti 1-10 in Fig. 2). Both S. bechsteini and S. myoti hosted by Natterer's bats were nested within the strongly supported clade IX, which contained all haplotypes of S. andegavinus (Fig. 2), i.e. those hosted by another bat species $M$. daubentonii. These results suggested that the $S$. myoti complex (i.e. including the Spinturnix of $M$. myotis, $M$. daubentonii, $M$. nattereri and $M$. capaccinii, sensu Rudnick, 1960) contained two biologically distinct species, one specific to $M$. myotis and M. blythii, and one to an unnamed taxon, specific to $M$. nattereri. This unnamed taxon might be conspecific with $S$. bechsteini, but appropriate morphometric comparisons are lacking. To further accommodate the phylogenetic results of Fig. 2 with the taxonomy, both S. bechsteini and the unnamed taxon might represent only subspecies of $S$. andegavinus hosted by Daubenton's bats. As all three bat species (M. daubentonii, M. bechsteinii and $M$. nattereri) are tree roosting bats that can be found in strict sympatry over wide areas in Europe (Dietz et al., 2007), this taxonomic assignment of the mite would also be consistent with the ecology of their hosts. At least, our molecular results call for a morphological revision of these closely related Spinturnix species.

\subsection{Host and parasite cophylogeny}

The distance-based analysis revealed a significant coevolutionary relationship between this peculiar host-parasite association. The comparison of mite and bat phylogenies confirms the relatively high (but not strict) host specificity of Spinturnicidae in western Europe. We observe three levels of parasite-host associations: (1) a mite species is associated with a single host species (e.g. S. punctata), or (2) with several congeneric species (e.g. S. plecotina); (3) a single mite species (e.g. S. psi) is associated with multiple hosts from distinct genera or even families (considering that Miniopterus bats have been recently elevated to a familial status, Miller-Butterworth et al., 2007). High host specificity has also been reported in spinturnicid mites of the genus Periglischrus (Acari, Spinturnicidae), parasitizing bats of the family Phyllostomidae (Sheeler-Gordon and Owen, 1999), and in Strebilidae (Diptera,
Streblidae), another obligate ectoparasite group of chiropterans (Dick, 2007).

Our results show that strict cospeciation does not explain all the current distribution of Spinturnicid mites. Several evolutionary events are indeed necessary to reconcile host and parasite phylogenies, such as failure to speciate and host switch events. We found five potential failures to speciate events, where one parasite species parasitized closely related host species without showing marked genetic differentiation (clade VI, VII, VIII, IX and XI; Fig. 3). These results are in accordance with several studies highlighting that the ancestral host species speciates without parallel speciation of its parasite. In this case, the parasite is still capable of exploiting both daughter species, resulting in one parasite species occurring on two related host species (lice with penguins: Banks et al., 2006; Pilgrim and Palma, 1982; nematodes with shrews: Brant and Orti, 2003; lice with pigeons and doves: Johnson et al., 2003). The greater and the lesser mouse-eared bats, M. myotis and $M$. blythii, are living in sympatry in some parts of Europe (Arlettaz et al., 1997). Despite clear parasite preference for $M$. myotis within mixed species colonies, $S$. myoti occurred also at high prevalence on M. blythii (Christe et al., 2003; Christe et al., 2007). The close physical association between host species in colonial roosts may permit to maintain gene flow between mites of these two host species. The absence of genetic differences in the parasites may also correspond to a very recent or to an incomplete host switching (Clayton et al., 2003; Ronquist, 2003). However, Hugot et al. (2001) suggested that failure to speciate are more parsimonious than host switching events in case the same parasite species parasitizes closely related host species. Likewise, the hosts themselves may have speciated too recently for their parasites to develop measurable genetic differences at the two essayed mitochondrial genes.

Intimate associations often increase the likelihood of mirrorimage phylogenies. The more specialized a parasite is, the more cospeciation events should occur and the more a parasite should mirror its host phylogeny (Brooks and McLennan, 1991; Klassen, 1992; Mitter and Brooks, 1983). Pocket gophers (Geomyidae) and lice (Trichodectidae) association is a good example of strict cospeciation (Hafner and Nadler, 1988; Hafner and Page, 1995; Hafner et al., 1994; Page and Hafner, 1996). However, an increasing number of studies showed that mismatches between host and parasite or co-occurring species are common (viruses and primates: Charleston and Robertson, 2002; worms and goby: Huyse and Volckaert, 2005; lice and birds: Johnson et al., 2001; fig wasps and figs: Weiblen and Bush, 2002). Strict cospeciation between host and parasite becomes even more unlikely when horizontal transmission occurs frequently. Indeed, several studies showed that host switching is an evolutionary event that can confound cospeciation pattern (Charleston and Robertson, 2002; Huyse and Volckaert, 2005; Weckstein, 2004).

According to the host and parasite phylogenies (Fig. 3), at least five host switch events were needed to reconcile the topologies. Three host switches involved a mite species parasitizing hosts from two different genera or even families of bats (clade II, V and X; Fig. 3). All three inferred host switches are incomplete or recent, as the mite populations on the two host species have not diverged genetically from each other. A common factor that might be involved in these host switches is the roosting habits of the bats, particularly during breeding when mite reproductive cycle follow the one of its host (Christe et al., 2000; Lourenco and Palmeirim, 2007; Lucan, 2006). Mixed-species breeding colonies with high females' aggregation are frequent (Krapp, 2001) and represent a main opportunity for mites to switch from one host species to another. For example, $R$. euryale is commonly found to roost together with M. emarginatus, or M. capaccinii with Min. schreibersii (Brosset, 1966; Deunff, 1977). Some host switches have even already been observed under natural conditions. Indeed E. euryalis is known to 
infest M. emarginatus in mixed swarm and S. psi was already found on M. capaccinii (Deunff, 1977; Deunff et al., 2004). The observed host switches could be favoured by the absence of the native parasite species in the studied geographical range. However, in these three cases, the native mite species were present in the area (less than $300 \mathrm{~km}$ ). Indeed, in Spain, S. emarginata infested Min. schreibersii, even if $S$. psi is distributed in south Portugal (Lourenco and Palmeirim, 2007) and northeast of Spain (Estradapena and Serracobo, 1991). In France, M. emarginatus is infested by E. euryalis despite the occurrence of S. emarginata (Deunff 1977) and finally $M$. capaccinii is infested by $S$. psi despite the presence of $S$. myoti (Stanyukovich, 1997). Nevertheless, sharing the same roost does not imply sharing the same parasite species. In France, we found within the same roost different bat species parasitized by different mite species (Fig. 1, locality 3). Mite competition, dispersal, colonization ability and host roosting preferences could all be factors favouring one particular host switch. In addition, we found two bat species harbouring two different mite species depending on their co-roosting bat and on their geographical location (Fig. 1, locality 2 and 3). However, we never found different mite species on the same host individual or among individuals of the same species within a colony. This may be due to competitive exclusion between parasite species.

The other two inferred host switch events on Fig. 3 are more difficult to interpret. $M$. brandtii is phylogenetically distantly related from M. mystacinus and M. alcathoe, and is the only European species that originated in the Nearctic region (Ruedi and Mayer, 2001). However, these three bat species are currently sympatric and share similar roosting ecologies (Dietz et al., 2007), enabling horizontal transmission of parasites between species. The Natterer's bat is also a forest-dwelling species with similar roosting habits as those of the Bechstein's bat (Siemers and Swift, 2006). Again, this ecological similarity may explain their closely related Spinturnix, while those two bats are not each other' closest relatives (Fig. 3) (Ruedi and Mayer, 2001).

Some mite species seem to be restricted to closely related bat species, while others can parasitize phylogenetically unrelated bats. For instance, S. plecotina parasitized only two species of Plecotus, whereas S. psi and S. emarginata parasitize bats from different host genera, probably as a consequence of host switching. Such contrasts in host preference were already demonstrated experimentally with $S$. myoti and $S$. andegavinus. Using cross-infection experiments, Giorgi et al. (2004) showed that the mite S. myoti exhibited a clear preference for its native bat host, $M$. myotis, while $S$. andegavinus displayed no host choice and colonized indifferently M. myotis or M. daubentonii. Our results support these contrasted preferences for host specificity. Indeed, if we consider the Spinturnix hosted by Natterer's bats as a species distinct from $S$. myoti (see above), $S$. myoti is restricted to two sister host species, M. myotis and M. blythii (clade XI, Fig. 3), whereas species from the S. andegavinus group can apparently parasitize three unrelated species (clade IX, Fig. 3).

\section{Conclusions}

Our results on the Spinturnicid - bat system provide evidence for cospeciation but also for other processes which do not involve speciation of the parasite. Mite dispersal ability, adaptation to a new host species, competition with other mite species and host social and roosting behaviours may be important factors shaping the current pattern of association between mites and their hosts. In presence of multi-host parasites, our study shows the importance to cover the natural range of species to unravel the history of an association (Tripet et al., 2002). One recent review reveals that Acari could be good candidates to study speciation events and host race formation, as they often intimately interacted with their hosts (Magalhaes et al., 2007). Moreover, these phenomena might be likely to occur when hosts are long-lived. Bats are long-lived species and it would be interesting to focus, in the future, on multihost mites to identify potential host race formation.

\section{Acknowledgments}

We are grateful to many people who assisted with the collection of specimens especially Fany Alba (Groupe Chiroptères de Provence), Mélanie Némoz (Mission Chiroptères Grand Sud), Grégory Beuneux (Groupe Chiroptères Corse), Juan Quetglas, Ana García Popa-Lisseanu, Carlos Ibanez, Javier Juste (Grupo de Ecología y Sistemática de Quirópteros, Sevilla), Juan Ramon \& Olvido (Malaga), Mauro Muccedda (Italy), Godefroy Devevey, Raphaël Arlettaz, Maud Giorgi, François Biollaz, Arnaud Maeder, Patrick Pattey, Susanna Szentkuti and Olivier Glaizot (Switzerland). We also thank Olivier Broennimann and two anonymous referees for their very useful comments in the article and Nicolas Salamin and P-A Christin for their help in the analysis.

\section{References}

Arlettaz, R., Ruedi, M., Ibanez, C., Palmeirim, J., Hausser, J., 1997. A new perspective on the zoogeography of the sibbling mouse-eared bat species M. myotis and $M$. blythii: Morphological, genetical and ecological evidence. J. Zool. (Lond.) 242, 45-62.

Baker, A.S., Craven, J.C., 2003. Checklist of the mites (Arachnida: Acari) associated with bats (Mammalia: Chiroptera) in the British Isles. Syst. Appl. Acarol. Spec. Publ. 14, 1-20.

Banks, J.C., Palma, R.L., Paterson, A.M., 2006. Cophylogenetic relationships between penguins and their chewing lice. J. Evol. Biol. 19, 156-166.

Barrett, M., Donoghue, M.J., Sober, E., 1991. Against consensus. Syst. Zool. 40, 486493.

Brant, S.V., Orti, G., 2003. Evidence for gene flow in parasitic nematodes between two host species of shrews. Mol. Ecol. 12, 2853-2859.

Brooks, D.R., McLennan, D.A. (Eds.), 1991. Phylogeny, Ecology and Behaviour: A Research Program in Comparative Biology. The University of Chicago press, Chicago.

Brosset, A. (Ed.), 1966. La biologie des Chiroptères. Masson et Cie, Paris.

Charleston, M.A., Robertson, D.L., 2002. Preferential host switching by primate lentiviruses can account for phylogenetic similarity with the primate phylogeny. Syst. Biol. 51, 528-535.

Christe, P., Arlettaz, R., Vogel, P., 2000. Variation in intensity of a parasitic mite (Spinturnix myoti) in relation to the reproductive cycle and immunocompetence of its bat host (Myotis myotis). Ecol. Lett. 3, 207-212.

Christe, P., Giorgi, M.S., Vogel, P., Arlettaz, R., 2003. Differential species-specific ectoparasitic mite intensities in two intimately coexisting sibling bat species: resource - mediated host attractiveness or parasite specialization? J. Anim. Ecol. 72, 866-872.

Christe, P., Glaizot, O., Evanno, G., Bruyndonckx, N., Devevey, G., Yannic, G., Patthey, P., Maeder, A., Vogel, P., Arlettaz, R., 2007. Host sex and ectoparasites choice. preference for, and higher survival on female hosts. J. Anim. Ecol. 76, 703-710.

Clayton, D.H., Al-Tamini, S., Johnson, K.P., 2003. The ecological basis of coevolutionary history. In: Page, R.D.M. (Ed.), Tangled Trees. Phylogeny, Cospeciation, and Coevolution. University of Chicago press, Chicago, pp. 310-341.

Combes, C., 1991. Evolution of parasite life cycles. In: Toft, C.A., Aeschlimann, A. Bolis, L. (Eds.), Parasite-Host Associations. Co-existance or Conflict? Oxford University Press, London, pp. 62-82.

Combes, C., 1997. Fitness of parasites: pathology and selection. Int. J. Parasitol. 27, $1-10$.

Cunningham, C.W., 1997. Is congruence between data partitions a reliable predictor of phylogenetic accuracy? Empirically testing an iterative procedure for choosing among phylogenetic methods. Syst. Biol. 46, 464-478.

Desdevises, Y., Morand, S., Jousson, O., Legendre, P., 2002. Coevolution between Lamellodiscus (Monogenea: Diplectanidae) and Sparidae (Teleostei): the study of a complex host-parasite system. Evolution 56, 2459-2471.

Deunff, J., 1977. Observations on Spinturnicidae of occidental paleartic region (Acarina, Mesostigmata) - specificity, distribution and repartition. Acarologia $18,602-616$.

Deunff, J., Keller, A., Aellen, V., 1986. A new spinturnicid mite found in Switzerland, Spinturnix helvetiae n. sp. (Acarina, Mesostigmata, Spinturnicidae), specific of the bat Nyctalus leisleri (Chiroptera, Vespertilionidae). Rev. Suisse Zool. 93, 803812 .

Deunff, J., Keller, A., Aellen, V., 1997. Redescription of Spinturnix punctata (Sundevall, 1833) (Acari, Mesostigmata, Spinturnicidae), a specific parasite of Barbastella barbastellus (Chiroptera, Vespertilionidae). Rev. Suisse Zool. 104, 199-206.

Deunff, J., Volleth, M., Keller, A., Aellen, V., 1990. Description of a new spinturnicid mite, Spinturnix nobleti n. sp. (Acari, Mesostigmata, Spinturnicidae), specific of 
Pipistrellus (Hypsugo) savii (Chiroptera, Vespertilionidae). Rev. Suisse Zool. 97, 477-488.

Deunff, J., Walter, G., Bellido, A., Volleth, M., 2004. Description of a cryptic species, Spinturnix bechsteini n. sp. (Acari, Mesostigmata, Spinturnicidae), parasite of Myotis bechsteinii (Kuhl, 1817) (Chiroptera, Vespertilionidae) by using ecoethology of host bats and statistical methods. J. Med. Entomol. 41, $826-832$.

Dick, C.W., 2007. High host specificity of obligate ectoparasites. Ecol. Entomol. 32, 446-450.

Dick, C.W., Patterson, B.D., 2007. Against all odds: explaining high host specificity in dispersal-prone parasites. Int. J. Parasitol. 37, 871-876.

Dietz, C., von Helversen, O., Nill, D. (Eds.), 2007. Die Fledermäuse Europas und Nordwestafrikas. Biologie, Kennzeichen, Gefährdung. Kosmos Verlag, Stuttgart.

Dubey, S., Salamin, N., Ohdachi, S.D., Barrière, P., Vogel, P., 2007. Molecular phylogenetics of shrews (Mammalia: Soricidae) reveal timing of transcontinental colonizations. Mol. Phylogenet. Evol. 44, 126-137.

Estradapena, A., Serracobo, J., 1991. The Acarinia and Nycteribidia zones of Miniopterus schreibersi Kuhl (Mammalia, Chiroptera) in the northeast of Spain. Folia Parasitologica 38, 345-354.

Gandon, S., Capowiez, Y., Dubois, Y., Michalakis, Y., Olivieri, I., 1996. Local adaptation and gene-for-gene coevolution in a metapopulation model. Proc. R. Soc. Lond. B Biol. Sci. 263, 1003-1009.

Gandon, S., Van Zandt, P.A., 1998. Local adaptation and host-parasite interactions. Trends Ecol. Evol. 13, 214-216.

Giorgi, M.S., Arlettaz, R., Guillaume, F., Nussle, S., Ossola, C., Vogel, P., Christe, P., 2004. Causal mechanisms underlying host specificity in bat ectoparasites. Oecologia 138, 648-654.

Gower, J.C., 1966. Some distance properties of latent root and vector methods used in multivariate analysis. Biometrika 53, 325-338.

Guindon, S., Gascuel, O., 2003. A simple, fast, and accurate algorithm to estimate large phylogenies by maximum likelihood. Syst. Biol. 52, 696-704.

Hafner, M.S., Nadler, S.A., 1988. Phylogenetic trees support the coevolution of parasites and their hosts. Nature 332, 258-259.

Hafner, M.S., Page, R.D.M., 1995. Molecular phylogenies and host-parasite cospeciation - gophers and lice as a model system. Philos. Trans. R. Soc. Lond. B Biol. Sci. 349, 77-83.

Hafner, M.S., Sudman, P.D., Villablanca, F.X., Spradling, T.A., Demastes, J.W., Nadler, S.A., 1994. Disparate rates of molecular evolution in cospeciating hosts and parasites. Science 265, 1087-1090.

Halanych, K.M., 1998. Considerations for reconstructing metazoan history: signal, resolution, and hypothesis testing. Am. Zool. 38, 929-941.

Hoofer, S.R., Van den Bussche, R.A., 2003. Molecular phylogenetics of the chiropteran family Vespertilionidae. Acta Chiropt. 5, 1-59.

Huelsenbeck, J.P., Bull, J.J., Cunningham, C.W., 1996. Combining data in phylogenetic analysis. Trends Ecol. Evol. 11, 152-158.

Huelsenbeck, J.P., Ronquist, F., Nielsen, R., Bollback, J.P., 2001. Evolution - Bayesian inference of phylogeny and its impact on evolutionary biology. Science 294, 2310-2314.

Hugot, J.P., Gonzalez, J.P., Denys, C., 2001. Evolution of the old world Arenaviridae and their rodent hosts: generalized host-transfer or association by descent? Infect. Genet. Evol. 1, 13-20.

Huyse, T., Poulin, R., Theron, A., 2005. Speciation in parasites: a population genetics approach. Trends Parasitol. 21, 469-475.

Huyse, T., Volckaert, F.A.M., 2005. Comparing host and parasite phylogenies: Gyrodactylus flatworms jumping from goby to goby. Syst. Biol. 54, 710-718.

Ibanez, C., Garcia-Mudarra, J.L., Ruedi, M., Stadelmann, B., Juste, J., 2006. The Iberian contribution to cryptic diversity in European bats. Acta Chiropt. 8, 277-297.

Jaenike, J., 1990. Host specialization in phytophagous insects. Annu. Rev. Ecol. Syst. 21, 243-273.

Johnson, K.P., Adams, R.J., Page, R.D.M., Clayton, D.H., 2003. When do parasites fail to speciate in response to host speciation? Syst. Biol. 52, 37-47.

Johnson, K.P., Moyle, R.G., Witt, C.C., Faucett, R.C., Weckstein, J.D., 2001. Phylogenetic relationships in the louse genus Penenirmus based on nuclear (EF-l alpha) and mitochondrial (COI) DNA sequences. Syst. Entomol. 26, 491497.

Juste, J., Ibanez, C., Munoz, J., Trujillo, D., Benda, P., Karatas, A., Ruedi, M., 2004. Mitochondrial phylogeography of the long-eared bats (Plecotus) in the Mediterranean Palaearctic and Atlantic Islands. Mol. Phylogenet. Evol. 31, 1114-1126.

Juste, J., Ibanez, C., Trujillo, D., Munoz, J., Ruedi, M., 2003. Phylogeography of Barbastelle bats (Barbastella barbastellus) in the western Mediterranean and the Canary Islands. Acta Chiropt. 5, 165-175.

Klassen, G.J., 1992. Coevolution: a history of the macroevolutionary approach to studying host-parasite associations. J. Parasitol. 78, 573-587.

Klompen, H., Lekvelshvili, M., Black, W.C., 2007. Phylogeny of parasitiform mites (Acari) based on rRNA. Mol. Phylogenet. Evol. 43, 936-951.

Kolenati, F.A. (Ed.), 1856. Die Parasiten des Chiropern. Rudolph Rohrers Erben, Brünn, Germany.

Krapp, F. (Ed.), 2001. Handbuch der Säugetiere Europas (Fledertiere I). AULA-Verlag $\mathrm{GmbH}$, Wiebelsheim, Germany.

Krasnov, B.R., Shenbrot, G.I., 2002. Coevolutionary events in the history of association between jerboas (Rodentia: Dipodidae) and their flea parasites. Isr. J. Zool. 48, 331-350.

Kumar, S., Tamura, K., Nei, M., 2004. MEGA3: integrated software for molecular evolutionary genetics analysis and sequence alignment. Brief. Bioinform. 5, 150-163.
Legendre, P., Anderson, M.J., 1998. Program DistPCoA. Département de sciences biologiques, Université de Montréal. Available from: <http://www.fas. umontreal.ca/biol/casgrain/en/labo/dispcoa.html>.

Legendre, P., Desdevises, Y., Bazin, E., 2002. A statistical test for host-parasite coevolution. Syst. Biol. 51, 217-234.

Lewis, P.O., 2001. A likelihood approach to estimating phylogeny from discrete morphological character data. Syst. Biol. 50, 913-925.

Li, G., Jones, G., Rossiter, S.J., Chen, S.F., Parsons, S., Zhang, S.Y., 2006. Phylogenetics of small horseshoe bats from east Asia based on mitochondrial DNA sequence variation. J. Mammal. 87, 1234-1240.

Lourenco, S.I., Palmeirim, J.M., 2007. Can mite parasitism affect the condition of bat hosts? Implications for the social structure of colonial bats. J. Zool. (Lond.) 273, $161-168$.

Lucan, R.K., 2006. Relationships between the parasitic mite Spinturnix andegavinus (Acari: Spinturnicidae) and its bat host, Myotis daubentonii (Chiroptera: Vespertilionidae): seasonal, sex- and age-related variation in infestation and possible impact of the parasite on the host condition and roosting behaviour. Folia Parasitol. (Ceske Budejovice) 53, 147-152.

Maddison, W.P., Maddison, D.R., 2004. Mesquite: a modular system for evolutionary analysis. Version 1.06. Available from: <http://mesquiteproject.org>.

Magalhaes, S., Forbes, M.R., Skoracka, A., Osakabe, M., Chevillon, C., McCoy, K.D., 2007. Host race formation in the Acari. Exp. Appl. Acarol. 42, 225-238.

Mangold, A.J., Bargues, M.D., Mas-Coma, S., 1998. Mitochondrial 16S rDNA sequences and phylogenetic relationships of species of Rhipicephalus and other tick genera among Metastriata (Acari: Ixodidae). Parasitol. Res. 84, 478484.

Mason-Gamer, R.J., Kellogg, E.A., 1996. Testing for phylogenetic conflict among molecular data sets in the tribe Triticeae (Gramineae). Syst. Biol. 45, 524-545.

McCoy, K.D., Boulinier, T., Tirard, C., Michalakis, Y., 2001. Host specificity of a generalist parasite: genetic evidence of sympatric host races in the seabird tick Ixodes uriae. J. Evol. Biol. 14, 395-405.

Miller-Butterworth, C.M., Murphy, W.J., O’Brien, S.J., Jacobs, D.S., Springer, M.S., Teeling, E.C., 2007. A family matter: conclusive resolution of the taxonomic position of the long-fingered bats, Miniopterus. Mol. Biol. Evol. 24, 15531561.

Mitter, C., Brooks, D.R., 1983. Phylogenetic aspects of coevolution. In: Futuyma, D.J., Slatkin, M. (Eds.), Coevolution. Sinauer, Sunderland, pp. 65-98.

Nadler, S.A., 1995. Microevolution and the genetic-structure of parasite populations. J. Parasitol. 81, 395-403.

Navajas, M., Le Conte, Y., Solignac, M., Cros-Arteil, S., Cornuet, J.M., 2002. The complete sequence of the mitochondrial genome of the honeybee ectoparasite mite Varroa destructor (Acari: Mesostigmata). Mol. Biol. Evol. 19, 2313-2317.

Nieberding, C., Libois, R., Douady, C.J., Morand, S., Michaux, J.R., 2005 Phylogeography of a nematode (Heligmosomoides polygyrus) in the western Palearctic region: persistence of northern cryptic populations during ice ages? Mol. Ecol. 14, 765-779.

Nieberding, C., Morand, S., Libois, R., Michaux, J.R., 2004. A parasite reveals cryptic phylogeographic history of its host. Proc. R. Soc. Lond. B Biol. Sci. 271, 25592568.

Nieberding, C.M., Durette-Desset, M.C., Vanderpoorten, A., Casanova, J.C., Ribas, A. Deffontaine, V., Feliu, C., Morand, S., Libois, R., Michaux, J.R., 2008. Geography and host biogeography matter for understanding the phylogeography of a parasite. Mol. Phylogenet. Evol. 47, 538-554.

Norris, D.E., Klompen, J.S.H., Keirans, J.E., Black, W.C., 1996. Population genetics of Ixodes scapularis (Acari: Ixodidae) based on mitochondrial $16 \mathrm{~S}$ and $12 \mathrm{~S}$ genes. J. Med. Entomol. 33, 78-89.

Nylander, J.A.A., 2006. MrModeltest 2.2., Dept. Systematic Zoology. EBC, Uppsala University, Sweden.

Page, R.D.M., 1994. Parallel phylogenies: reconstructing the history of host-parasite assemblages. Cladistics 10, 155-173.

Page, R.D.M., Charleston, M.A., 1998. Trees within trees: phylogeny and historical associations. Trends Ecol. Evol. 13, 356-359.

Page, R.D.M., Hafner, M.S., 1996. Molecular phylogenies and host-parasite cospeciation: gophers and lice as a model system. In: Harvey, P.H., LeighBrown, A.J., Maynard Smith, J., Nee, S. (Eds.), New Uses for New Phylogenies. Oxford University Press, Oxford, pp. 255-270.

Parker, S.R., 1997. Sequence navigator. Multiple sequence alignment software. Methods Mol. Biol. 70, 145-154.

Paterson, A.M., Banks, J., 2001. Analytical approaches to measuring cospeciation of host and parasites: through a glass, darkly. Int. J. Parasitol. 31, 1012-1022.

Pilgrim, R.L.C., Palma, R.L., 1982. A list of the chewing lice (Insecta: Mallophaga) from birds in New Zealand. Notornis 29 (34), 1-32.

Poulin, R., Krasnov, R., Morand, S., 2006. Pattern of host specificity in parasites exploiting small mammals. In: Morand, S., Krasnov, B.R., Poulin, R. (Eds.), Micromammals and Macroparasites. Springer-Verlag, Tokyo, pp. 235-256.

Reckardt, K., Kerth, G., 2007. Roost selection and roost switching of female Bechstein's bats (Myotis bechsteinii) as a strategy of parasite avoidance. Oecologia 154, 581-588.

Rodriguez, F., Oliver, J.L., Marin, A., Medina, J.R., 1990. The general stochastic-model of nucleotide substitution. J. Theor. Biol. 142, 485-501.

Ronquist, F., 2003. Parsimony analysis of coevolving species associations. In: Page, R.D.M. (Ed.), Tangled Trees. Phylogeny, Cospeciation and Coevolution. University of Chicago press, Chicago, pp. 22-64.

Rudnick, A., 1960. A revision of the mites of the family Spinturnicidae. University of California Press 17, 157-284. 
Ruedi, M., Mayer, F., 2001. Molecular systematics of bats of the genus Myotis (Vespertilionidae) suggests deterministic ecomorphological convergences. Mol. Phylogenet. Evol. 21, 436-448.

Sambrook, J.E., Fritsch, F., Manitatis, T. (Eds.), 1989. Molecular cloning: a laboratory manual, second ed. Cold Spring Harbor Laboratory Press, New York

Schober, W., Grimberger, E. (Eds.), 1991. Guide des chauves-souris d'Europe. Delachaux et Niestlé, Lausanne.

Sheeler-Gordon, L.L., Owen, R.D., 1999. Host tracking or resource tracking? The case of Periglischrus wing mites (Acarina: Spinturnicidae) of leaf-nosed bats (Chiroptera: Phyllostomidae) from Michoacan, Mexico. Acta Zoologica Mexicana (n.s.) 76, 85-102.

Siemers, B.M., Swift, S.M., 2006. Differences in sensory ecology contribute to resource partitioning in the bats Myotis bechsteinii and Myotis natterer (Chiroptera: Vespertilionidae). Behav. Ecol. Sociobiol. 59, 373-380.

Simon, C., Frati, F., Beckenbach, A., Crespi, B., Liu, H., Flook, P., 1994. Evolution, weighting, and phylogenetic utility of mitochondrial gene-sequences and compilation of conserved polymerase chain-reaction primers. Ann. Entomol. Soc. Am. 87, 651-701.

Stadelmann, B., Jacobs, D.S., Schoeman, C., Ruedi, M., 2004. Phylogeny of African Myotis bats (Chiroptera, Vespertilionidae) inferred from cytochrome $b$ sequences. Acta Chiropt. 6, 177-192.

Stanyukovich, M.K., 1997. Keys to the gamasid mites (Acari, Parasitiformes, Mesostigmata, Macronyssoidea et Laetaptoidea) parasitizing bats (Mammalia, Chiroptera) from Russia and adjacent countries. Rudolstädter nat. hist. Schr 7, 13-46.

Struck, T.H., Purschke, G., Halanych, K.M., 2006. Phylogeny of Eunicida (Annelida) and exploring data congruence using a partition addition bootstrap alteration (PABA) approach. Syst. Biol. 55, 1-20.

Swofford, D.L., 1998. PAUP*. Phylogenetic analysis using Parsimony ( $*$ and others methods), Version 4.0b1. Sinauer Associates, Sunderland, Massacusetts.
Teeling, E.C., Springer, M.S., Madsen, O., Bates, P., O’Brien, S.J., Murphy, W.J., 2005. A molecular phylogeny for bats illuminates biogeography and the fossil record. Science 307, 580-584

Thompson, J.N. (Ed.), 1994. The Coevolutionary Process. University of Chicago Press, Chicago.

Tripet, F., Christe, P., Moller, A.P., 2002. The importance of host spatial distribution for parasite specialization and speciation: a comparative study of bird fleas (Siphonaptera: Ceratophyllidae). J. Anim. Ecol. 71, 735-748.

Uchikawa, K., Zhang, M.-Y., O'Connor, B.M., Klompen, H., 1994. Contribution to the taxonomy of the genus Spinturnix (Acari: Spinturnicidae), with the erection of a new genus, Emballonuria. Folia Parasitol. (Ceske Budejovice) 41, 287-304.

Vinarski, M.V., Korallo, N.P., Krasnov, B.R., Shenbrot, G.I., Poulin, R., 2007. Decay of similarity of gamasid mite assemblages parasitic on Palaearctic small mammals: geographic distance, host-species composition or environment. J. Biogeogr. 34, 1691-1700.

Ward, S.A., Leather, S.R., Pickup, J., Harrington, R., 1998. Mortality during dispersal and the cost of host-specificity in parasites: how many aphids find hosts? J. Anim. Ecol. 67, 763-773.

Weckstein, J.D., 2004. Biogeography explains cophylogenetic patterns in toucan chewing lice. Syst. Biol. 53, 154-164.

Weiblen, G.D., Bush, G.L., 2002. Speciation in fig pollinators and parasites. Mol. Ecol. 11, 1573-1578.

Wheeler, W.C., Ramirez, M.J., Aagesen, L., Schulmelster, S., 2006. Partition-free congruence analysis: implications for sensitivity analysis. Cladistics 22, 256263.

Yang, Z.H., 1996. Phylogenetic analysis using parsimony and likelihood methods. J. Mol. Evol. 42, 294-307.

Yoder, A.D., Irwin, J.A., Payseur, B.A., 2001. Failure of the ILD to determine data combinability for slow loris phylogeny. Syst. Biol. 50, 408-424. 